\title{
A Business Model Assessment and Evaluation Framework for City Logistics Collaborative Strategic Decision Support
}

\author{
Giovanni Zenezini ${ }^{1}$, Jesus Gonzalez-Feliu ${ }^{2}$, Giulio Mangano ${ }^{1}$ and Laura Palacios- \\ Arguello ${ }^{2}$ \\ ${ }^{1}$ Department of Management and Production Engineering, Politecnico di Torino, Italy \\ \{giovanni.zenezini, giulio.mangano\}@polito.it \\ ${ }_{2}$ Henri Fayol Institute, Ecole de Mines de St.Etienne, France \\ \{jesus.gonzalez-feliu, laura.palacios\}@emse.fr
}

\begin{abstract}
Several City Logistics (CL) initiatives have emerged in the last two decades with the aim to reduce the negative externalities of freight distribution in urban areas. Such initiatives can be public and/or private but need to not break or impeach current operations efficiency so to not hinder their profitability. In order to provide business value to CL initiatives and thus fostering their long-term success, it is necessary to understand the decisionmaking of private companies operating in the urban freight ecosystem. This paper proposes an ex-ante assessment and evaluation framework built around the concept of an ecosystem business modelling that includes the decisionmaking by CL stakeholders. A theoretical framework previously developed is extended to evaluate a collaborative business model of an Urban Consolidation Centre (UCC). Cost-Benefit analysis (CBA is used estimate the impact of the business model configuration. Finally, research and practice implications are also addressed.
\end{abstract}

Keywords: City Logistics; Business Model; Cost-Benefit Analysis; Consolidation Centre

\section{Introduction}

Collaboration among various stakeholders is a crucial subject in operations, business and logistics management. In urban logistics, the issue of identifying stakeholders and examining the most suitable ways of collaboration among them has started to be addressed, mainly in the form of optimization models or in a qualitative way. However, the key of success of such collaboration is strongly related to reaching a solid business model. Designing and assessing a solid long-term collaborative business model is therefore of vital importance for closing this gap and turn CL innovative solutions into sustainable, large-scale endeavors.

When dealing with cutting-edge innovations business models need to be assessed, both qualitatively (to identify levers and limits) and quantitatively (to examine their economic viability). Although business model deployment is popular in logistics and starts being applied to CL $[1,2]$, they are far to propose a systematic, unified 
approach that would address the collaboration issues. Furthermore, its assessment remains little done as existing works make it either on a qualitative or quantitative way only, without combining both approaches $[3,4]$.

The aim of this paper is thus to propose a methodological framework to analyze the potential BM in collaborative CL; being able to identify stakeholders, key elements and cost-benefit issues to develop and assess a suitable business model for city logistics collaboration. First, the background and literature related to that subject, i.e. urban logistics assessment and evaluation, stakeholder collaboration and business model assessment are presented. Then, the methodological frameworks is presented. After that, an example of application is presented via a case study for a university collaborative consolidation center for B2C flows. Finally, as a conclusion, research and practice implications are presented.

\section{Research Background and Theoretical Framework}

The literature section provides the theoretical background upon which the assessment framework is built. In the first section the most important aspects of collaboration in logistics are explored, in order to define the nature of such collaboration. Business modelling in CL context is explored in the following section, focusing on the potential case application and the shortcomings that convey the need for an innovative approach for CL evaluation. Finally, the Cost-Benefit Analysis (CBA) method is explained in section 2.3.

\subsection{Stakeholders' Collaboration in Logistics}

In city logistics, the subject of multi-stakeholder collaboration has been widely addressed by various authors [5]. Given the multiple stakeholders involved in urban logistics, the collaboration among them can be of different nature (public-public, public-private or private-private), and arise at different level (transactional, informational, decisional, i.e. dealing with strategic, tactical or operational planning [6]). Logistics collaboration can be observed from different viewpoints:

- By its object, the collaboration can be informational, infrastructure-based, based on purchases or vehicle-based [7].

- By the organizational aspects, which are closely related to the functions of the supply chain that are shared [8]: longitudinal collaboration, which takes place between complementary actors in the same logistics chain; and transversal collaboration, often takes place between actors at the same level but not necessarily in the same supply chain.

In both cases, collaboration can be formal (on the basis of contracts [9]) or informal (without a legal base) but supposes important organizational, technological and cultural changes, which can impact the business model of the supply chain or proposed solutions.

Various authors have studied public-private collaboration, on a wide viewpoint [10], concluding on the need of assessing the value of those partnerships and the need 
of collaboration to establish them in a sustainable way. That can be done via the definition of business models [11] that can support the consensus search procedures [7], but to make final choices, decision support methods are required, as shown in the conceptual framework proposed by [12].

\subsection{Business Model Theory and Usage in CL Context}

The concept of Business Modelling (BM) relates to theoretical frameworks able to assess the potential economic value that an organization can create by selling a product or service [13]. [14] center their business model framework proposition on four different components, namely customer value proposition, profit, key resources, and key process. Hence, in summary a business model includes the following components: a value proposition and a revenue model adopted to gain a share of the value created [15]; a value chain including key resources, key processes and key partners; and finally a cost structure.

The business model approach has been applied so far by few CL scholars. [2] assessed an automated parcel lockers (APL) solution by means of the Business Model Canvas (BMC), one of the most used BM framework proposed by Osterwalder and Pigneur (2010). Through the BM framework, the authors highlight the value proposition offered to both customers and society, in addition to constructing a business case according to different business model scenario. According to [17], the value proposition of a last-mile service aggregates different components such as price, order lead-time, service quality, scope of service, sustainability and other benefits including cost reduction convenience or flexibility of service. The BMC has been also used by [1] to assess the feasibility of an investment in a shared, multi-stakeholder digital platform for CL management. However, [18] argue that accounting for the different goals of CL stakeholders is out of the scope of the BMC, which thus shows some shortcomings in terms of assessing the overall feasibility of a CL solution.

\subsection{Ex-Ante Evaluation of CL with CBA}

To evaluate the suitability of business models, it is important to assess the costs and benefits generated by it, and find the economic equilibrium and potential monetary gains/losses [3]. One of the most used technique in transport infrastructure or passenger transport systems long-term assessment is Cost-Benefit analysis (CBA). However, CBA was very little used in city logistics until 2012 [4], but is starting to be generalized since then. It has been used to evaluate if the benefits delivered by a new transportation infrastructure exceed the costs and determined an efficient allocation of resources [19]. CBA has mainly been applied to assess the economic viability of urban consolidation centers, to define suitable fees for new urban logistics systems or also to define an economically viable urban freight railway system, among others [4, 20], and also to obtain the suitable value of fees for the use of technology-based city logistics services [3]. Main works on CBA deal with investment-based methods, but 
also operational planning methods, based on marginal cost analysis, have been seen in CL [12].

\section{Methodology}

The tenets of the proposed methodology are as follows. First, CL systems are interpreted as business ecosystems, characterized by the interplay between stakeholders' activities, decisions and objectives. In order to respond to this challenge we propose a classification of CL stakeholders according to the main activities performed or space they occupy in the ecosystem $[12,17]$ :

- The first group includes the transport demand generators, who generate demand and use the transport and logistics services (e.g. citizens, local retailers and shippers);

- The second group includes the service providers, or transport operators, who are appointed by shippers or receivers to deliver parcels and other goods (e.g. express couriers such as DHL and the like, small city transport ompanies);

- The third group comprise those stakeholders who are in charge of coordinating the network, or interface roles. Usually transport providers provide coordination services but, in some cases, intermediary platforms or public authorities can take on this role.

- The fourth and last group includes the stakeholders who manage and plan the logistics space, or space organizers. They comprise public authorities in charge of land use planning and real estate facility managers aiming to increase the quality of life of their employees or tenants.

The categories identified aggregate functions and activities necessary in a CL business ecosystem, and can be defined as roles [17].

The second tenet of the proposed framework ensues as a consequence of the first one: the same CL solution can be implemented through different business model configurations where stakeholders take up different roles and exchange different value propositions. A specific business model configuration determines which stakeholder takes certain decisions and invest in resources, as well as the collaboration links between stakeholders. In turn, the business model configuration chosen has an impact on activity execution and the success of the collaboration between the stakeholders measured via proper metrics. Table 1 summarizes the main elements of a collaborative CL business ecosystem.

Table 1 Main components of a CL business ecosystem

\begin{tabular}{|c|c|}
\hline Component & Operational description \\
\hline Resource & They are owned by stakeholders. \\
\hline Activity & Activities are performed to offer services, and consume resources. \\
\hline Metric & $\begin{array}{l}\text { KPIs measure the business objects (e.g. activities, value } \\
\text { proposition). }\end{array}$ \\
\hline Decision & $\begin{array}{l}\text { Stakeholders make decisions in the fulfilment of their roles, based } \\
\text { on a set of constraints, variables, decision parameters. }\end{array}$ \\
\hline Service & Aggregation of activities that use resources and are role-based. \\
\hline
\end{tabular}


The next step of the methodology is the assessment of the business model, or the quantification of the effects on all stakeholders of the business ecosystem role-playing and linkages between the stakeholders themselves. A suitable method to validate a Business Model is the Cost-Benefit Analysis [3]. For an exploratory approach, instead of using long-term IRR-based (internal return rate) frameworks [3], we propose a cashflow analysis, which is widely used in business research and presents a more aggregated vision than marginal cost analyses [12] making it suitable for strategic/tactical planning purposes [21]. In the proposed framework, costs and benefits are calculated in a monetary value $(€)$ and only real, and direct monetary cashflows are estimated. More precisely, costs are accrued by the stakeholders according to the activities they perform as well as the investment committed to acquire the resources they use. Benefits are instead represented through the exchange of value proposition among the stakeholders, expressed in monetary terms, and the actual inflow of revenues. The cashflow analysis estimated then the monetary values, in a 1-year horizon, for each quarter. Then, each quarter's net cashflow is calculated, to examine its evolution. The proposed methodology for designing and assessing a CL business ecosystem business model is shown in Figure 1.

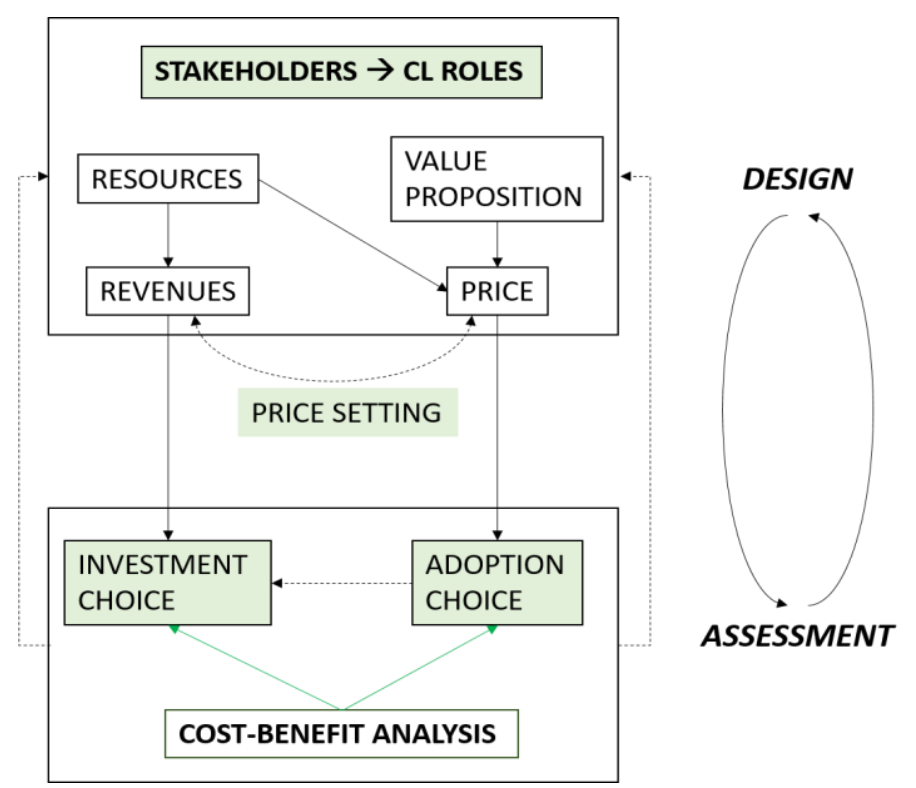

Fig. 1 Methodology for designing and assessing a CL business ecosystem business model

\section{Case Study}

The proposed case study hinges on an internal consolidation center, sized approximately $20 \mathrm{~m}^{2}$, located in the Politecnico di Torino, the technical university of 
Turin, Italy. The center's operations are subcontracted to an external logistics service provider (LSP), and is focused on receiving deliveries for all employees (about 2000 people) and sorting them to the university departments.

\subsection{Business and Operational Model}

The center handles two different kinds of deliveries: the institutional ones refer to work-related purchases and are delivered from the center to the departments, and the private ones. For the latter, the employees must go to the center for the picking. In the center, one employee works full time, flanked by two part- time workers in the morning. Even though there are 8 LSPs serving the consolidation center, each LSP typically associate the same driver to the route that includes the center. For most LSPs, the drivers are employees of local freight operators who the LSPs sub-contract the last-mile of the delivery. All the parcels accepted are identified via QR system, and the software automatically sends an e-mail to the final receiver through the internal e-mail system. When he/she arrives in the consolidation center, thorough a digital signature the final delivery is registered and it is traced by the software.

By delivering to an operated consolidation center, the LSPs are sure that the deliveries will not fail, and at the same time, the employees have the whole working day available for the picking. Moreover, LSPs can optimize their routing by consolidating more deliveries in a lower number of stop and thus can increase their routing efficiency. Finally, final customers (or end-consumers) simply update the delivery location to the center and thus do not incur in extra costs with the inclusion of the new platform. Table 2 summarizes the main roles played by the stakeholders in this CL ecosystem, and highlights that all costs are borne by the employer (i.e. the university) while all potential benefits are scattered across the whole ecosystem.

Table 2 Stakeholders, roles, costs and benefits for the pickup point solution, compared with the status quo (without the pickup point)

\begin{tabular}{|c|c|c|c|}
\hline Stakeholders & Role(s) & Costs & Benefits \\
\hline \multirow[t]{2}{*}{$\begin{array}{l}\text { Consolidation } \\
\text { center operator }\end{array}$} & Receiver & $\begin{array}{l}\text { One full-time and three } \\
\text { part-time employees }\end{array}$ & \multirow[t]{2}{*}{ Subcontracting fee } \\
\hline & $\begin{array}{l}\text { Network } \\
\text { Coordination }\end{array}$ & $\begin{array}{l}\text { Mobile terminal for } \\
\text { delivery management }\end{array}$ & \\
\hline Employer & $\begin{array}{l}\text { Real Estate } \\
\text { management }\end{array}$ & $\begin{array}{l}\text { Investment in logistics } \\
\text { spaces and equipment } \\
\text { Subcontracting fee }\end{array}$ & $\begin{array}{l}\text { Less congestion } \\
\text { More attractive } \\
\text { environment } \\
\text { Employees' satisfaction }\end{array}$ \\
\hline $\begin{array}{l}\text { Express } \\
\text { couriers }\end{array}$ & $\begin{array}{l}\text { Logistics } \\
\text { service provider }\end{array}$ & $\begin{array}{l}\text { No change from the } \\
\text { status quo }\end{array}$ & $\begin{array}{l}\text { Increase in routing } \\
\text { efficiency }\end{array}$ \\
\hline Local carriers & City delivery & $\begin{array}{l}\text { No change from the } \\
\text { status quo }\end{array}$ & $\begin{array}{l}\text { Better working condition } \\
\text { for drivers }\end{array}$ \\
\hline Online retailers & $\begin{array}{l}\text { User of logistics } \\
\text { service }\end{array}$ & $\begin{array}{l}\text { No change from the } \\
\text { status quo }\end{array}$ & $\begin{array}{l}\text { Certainty of delivery to } \\
\text { final customer }\end{array}$ \\
\hline Employees & $\begin{array}{l}\text { User of logistics } \\
\text { service }\end{array}$ & $\begin{array}{l}\text { No change from the } \\
\text { status quo }\end{array}$ & $\begin{array}{l}\text { Certainty of receiving the } \\
\text { ordered items }\end{array}$ \\
\hline
\end{tabular}


The proposed case study shows an interesting example of informational collaboration. As shown, a central stakeholder, the university, proposes an infrastructure assuming the costs and subcontracting a logistics service provider to manage the consolidation center, however for its operational planning a real informational collaboration system is established. Indeed, delivery companies arrive to the consolidation center and rely on the university's employees for steering and operating the system. For that reason, a strong communication among each delivery company and the users is required. In this regard, , receiving the same driver for each LSP every day helps the relationship between the drivers and the employees of the consolidation centers and thus improves the quality of the working conditions for both parties. Delivery companies organize their delivery schedules in relation to free space and customers' uses. For that reasons, an optimal use of the facility would require a more reactive and integrated information system.

\subsection{Collaboration Risks}

In order to enhance that collaboration, a traceability or availability information system would support that informational collaboration. However, some risks ensue from this kind of collaboration [6].

For this particular logistics collaboration, we do not presume significant technological risks. This consideration is due to the use of well-consolidated mobile terminal technology deployed by the Consolidation center operator for the Delivery Management. In fact, the process of receiving the parcel involves only reading the parcel barcode and updating automatically the information on a spreadsheet. This technology moreover does not depend on the extant information systems of logistics service providers, which will manage their own information flow embedded in the delivery process and transmit the information up to the shipper. Hence, the final recipient will receive a double notification of the delivery i.e. from their shipper and from the consolidation center operator. Some risks on the other hand might arise from the management of the resources, since at least three employees are needed at any time from the consolidation center. If, by any chance, the operator would not be able to provide enough human resources the center could not be operated. Should the operator not inform the LSPs of its disruption in the service then the LSP would waste time by stopping at the University. This risk is then correlated to the process-related risks, in the sense that LSPs permanently changed their routing after the introduction of the center. As a consequence, not informing them of the disruption will end up in a failed delivery (and consequently a return to the LSP's warehouse), and a longer delivery tour. The center operator must then collaborate closely with the LSP and inform them of any disruption or change in the service in order to assure the success of the collaboration. 


\subsection{Cost-Benefit Analysis Results}

To propose a first step into the CBA application via cashflow analysis, we aim to identify the costs and earnings of the proposed collaborative urban logistics space. For that analysis, we need first to identify the cost structure for each of the stakeholders whose cashflows are affected by the center, namely:

1. Logistics providers, for which no new incoming flows are expected, but whose outcoming flows can vary (mainly decrease) because of an efficiency improvement due to the use of the platform; that improvement (in terms of distances, times and vehicle use) will be modeled using the flow estimation approach shown in [12];

2. The host institution of the platform, here Politecnico di Torino, who operates the center through the subcontractor and whose costs are estimated to be around $450 €$ (on the basis of an empirical calculation based on local manpower and rental costs).

We take into account that the only costs related to transport that need to be calculated are those of logistics providers. Using the general framework of flow estimation (via analytical models) of [22], we estimate the number of end-consumers not visited at home and consolidated into the platform, and the resulting changes on transport flows. The platform receives an average number of 150 deliveries/day, which are then split according to each LSP's national market share [23]. Moreover, we assume an average number of 45 deliveries per vehicle per day (for classical B2C deliveries) and a total capacity of about 100 deliveries per vehicle per route [12]. Then, using the costs of transport in the geodelivery-Territoire Platform ${ }^{1}$, we estimate the main unitary costs, and then estimate the main transport costs of routes.

We observe, for each carrier, a gain of 10 to $45 \mathrm{~km} /$ day, which, when converted into cost (and then taking into account manpower and time-based costs), leads to a decrease of outcoming cashflows of 30 to 140 euros/day, with a total outcoming cashflow gain of $545 €$. It is important to note that for 7 of the 8 carriers, the demand of the platform does not allow to dedicate a specific vehicle, and for one of them the reorganization allows to have a dedicated vehicle with a potential gain of $140 € /$ day. As shown above, although the platform manages a small amount of deliveries nowadays (about $0,3 \%$ of total deliveries for Turin's area), cost gains of that reorganization are not negligible for carriers, and would increase widely if the number of deliveries increase or a network organization (for this type of platforms) is deployed.

\section{Discussion and Conclusion}

The proposed methodology aims to provide a framework for designing, assessing and validating the business model of a CL innovation from a multi-stakeholder's perspective. The framework is used to design a systemic business model taking into consideration a collaborative network of stakeholders, and then validate each

\footnotetext{
${ }^{1}$ https://territoire.emse.fr/solutions/?type=geodelivery
} 
stakeholder's business model by means of a cost-benefit analysis. Therefore, the framework allows designing different business model configurations while demonstrating the economic "winners" and "losers". The framework thus enables to propose a correct allocation of resources and benefits so to increase the chance of a widespread diffusion. The framework has been applied to a consolidation center operated by a northern Italian university, which allows its employees to pickup their e-commerce deliveries at the more convenient times and benefits the route optimization of LSPs. The CBA calculation have indeed proven that LSPs reduce their operating costs, and thus proposed methodology enables to shed light on an apparent opportunism of LSPs and final customers alike, who reap the benefits and do not share the costs. On the other hand, those costs are all borne by the University.

The main research and practical implications are the following. First, the framework is able to identify stakeholders, their roles and their relations, as well as to define the main investment and adoption choices. This will lead to a unified tool to assess the suitability of business models and support consensus search. Moreover, this case study serves as a testbed for the assessment methodology, which will be used for other collaborative logistics case studies in the future. Nevertheless, it might provide a best practice not only for other universities but also for other publicly-operated facilities (e.g. hospitals, central administration offices, ministries etc.) which account for a significant share of employment and could improve last-mile systems.

However, the framework is at a preliminary stage and needs an in-depth investigation of cost structures and cost-benefit assessment elements that will be done in a further research. The main goal of future research will be directed towards making the framework as a decision-making support tool for both private and public CL stakeholders.

\section{References}

1. De Marco, A., Mangano, G., Zenezini, G., Cagliano, A.C., Perboli, G., Rosano, M., Musso, S.: Business Modeling of a City Logistics ICT Platform. In: 41st Annual IEEE Computer Software and Applications Conference (COMPSAC). pp. 783-789. IEEE (2017). https://doi.org/10.1109/COMPSAC.2017.76.

2. Quak, H., Balm, S., Posthumus, B.: Evaluation of City Logistics Solutions with Business Model Analysis. Procedia - Soc. Behav. Sci. 125, 111-124 (2014). https://doi.org/10.1016/j.sbspro.2014.01.1460.

3. Gonzalez-Feliu, J., Basck, P., Morganti, E.: Urban logistics solutions and financing mechanisms: a scenario assessment analysis. Eur. Transp. Eur. 54, 1-16 (2013).

4. van Duin, J.H.R., Quak, H., Muñuzuri, J.: Revival of Cost Benefit Analysis for Evaluating the City Distribution Center Concept. In: Innovations in city logistics. pp. 97-114. Nova Science, New York (2008).

5. Lindawati, van Schagen, J., Goh, M., de Souza, R.: Collaboration in urban logistics: motivations and barriers. Int. J. Urban Sci. 18, 278-290 (2014).

6. Gonzalez-Feliu, J., Morana, J.: Collaborative transportation sharing: from theory to practice via a case study from France. In: Technologies for supporting reasoning communities and collaborative decision making: Cooperative approaches. pp. 252-271. IGI Global (2011). 
7. Gonzalez-Feliu, J., Morana, J., Grau, J.-M.S., Ma, T.-Y.: Design and scenario assessment for collaborative logistics and freight transport systems. Int. J. Transp. Econ. internazionale di Econ. dei Trasp. 207-240 (2013).

8. Pan, S., Ballot, E., Fontane, F.: The reduction of greenhouse gas emissions from freight transport by pooling supply chains. Int. J. Prod. Econ. 143, 86-94 (2013).

9. Lambert, D.M., Emmelhainz, M.A., Gardner, J.T.: Developing and implementing supply chain partnerships. Int. J. Logist. Manag. 7, 1-18 (1996).

10. Quak, H., Lindholm, M., Tavasszy, L., Browne, M.: From freight partnerships to city logistics living labs-Giving meaning to the elusive concept of living labs. Transp. Res. Procedia. 12, 461-473 (2016).

11. Macário, R., Galelo, A., Martins, P.M.: Business models in urban logistics. Ing. y Desarro. 77-96 (2008).

12. Gonzalez-Feliu, J.: Sustainable Urban Logistics: Planning and Evaluation. John Wiley \& Sons (2018).

13. Afuah, A.: Business models: A strategic management approach. McGraw-Hill/Irwin. New York (2004).

14. Johnson, M.W., Christensen, C.M., Kagermann, H.: Reinventing your business model. Harv. Bus. Rev. 86, (2008). https://doi.org/10.1111/j.0955-6419.2005.00347.x.

15. Amit, R., Zott, C.: Value creation in e-business. Strateg. Manag. J. 22, 493-520 (2001). https://doi.org/10.1002/smj.187.

16. Osterwalder, A., Pigneur, Y.: Business Model Generation: A Handbook for Visionaries, Game Changers, and Challengers. John Wiley and Sons Inc., New York, USA (2010). https://doi.org/10.1523/JNEUROSCI.0307-10.2010.

17. Zenezini, G.: A new evaluation approach to City Logistics projects - A business-oriented Agent-Based model, (2018).

18. Cagliano, A.C., De Marco, A., Mangano, G., Zenezini, G.: Assessing city logistics projects: A business-oriented approach. In: Proceedings of the Summer School Francesco Turco. , 13-15 September 2016, Napoli (Italy) (2016).

19. Suksri, J., Raicu, R.: Developing a Conceptual Framework for the Evaluation of Urban Freight Distribution Initiatives. Procedia - Soc. Behav. Sci. Seventh Int. Conf. City Logist. which was held June 7- 9,2011, Mallorca, Spain. 39, 321-332 (2012). https://doi.org/http://dx.doi.org/10.1016/j.sbspro.2012.03.111.

20. Gonzalez-Feliu, J.: A joint freight catchment and cost benefit analysis to assess rail urban logistics scenarios. In: International Conference on Information Systems, Logistics and Supply Chain. pp. 14-27 (2016).

21. DIXON, T.: COMPUTER SOFTWARE AVAILABILITY FOR VALUATION (Property Valuation, Development Appraisal and Portfolio Analysis). J. Valuat. 4, 21-32 (1986).

22. Gonzalez-Feliu, J.: Sustainable Urban Logistics. John Wiley and Sons Inc. (2018). https://doi.org/10.1002/9781119421948.

23. AGCOM: Servizio Economico Statistico. (2018). 